\title{
O espectro da Lei de Bronze: uma reflexão sobre a teoria política de Robert Michels por meio do contextualismo social
}

Jhonathan Matheus Dias ${ }^{1}$ Geraldo Magella Neres ${ }^{2}$

\begin{abstract}
Resumo: A obra de Robert Michels, denominada Sociologia dos partidos políticos, publicada originalmente em alemão em 1911, é um estudo feito com base na investigação empírica do Partido Socialdemocrata Alemão (SPD), por meio do qual Michels constrói sua famosa "Lei de Bronze" da burocratização e oligarquização de toda organização social complexa. Passados mais de 100 anos de sua formulação, o espectro da lei de bronze continua a aparecer nos debates acerca das organizações humanas. Compreendendo esse duradouro legado e sua relevância, o presente artigo tem como objetivo central apresentar a possibilidade de uso da teoria michelsiana para além da forma como é comumente evocada, como um meio de justificação ao abandono do ideal democrático. Com isso, pretende-se, por meio do uso do contextualismo social, evidenciar o potencial da obra de Michels como um importante mecanismo de reflexão no complexo processo de formulação das instituições representativas no século XXI.
\end{abstract}

Palavras-chave: Contextualismo Social; Democracia; Oligarquias; Representação.

\section{The spectrum of the Iron Law: A reflection on Robert Michels political theory through social contextualism}

\begin{abstract}
Robert Michels's work, called Sociology of Political Parties, published in German in 1911, is a study based on the empirical investigation of the German Social Democratic Party (SPD), through which Michels builds his famous "Bronze Law" of bureaucratization and oligarchization of any complex social organization. More than 100 years after its formulation, the specter of the bronze law continues to appear in debates about human organizations. Understanding this lasting legacy and its relevance, the present article has as central objective to present the possibility of using the michelsian theory beyond the way it is usually evoked, as a means of justification to abandonment of the democratic ideal. With this, it is intended to make use of social contextualism, to highlight the potential of Michels' work as an important reflection mechanism in the complex process of formulation of representative institutions in the $21 \mathrm{st}$ century.
\end{abstract}

Keywords: Social Contextualism; Democracy; Oligarchies; Representation.

\footnotetext{
${ }^{1}$ Graduado em Ciências Sociais na Universidade Estadual do Oeste do Paraná (Unioeste), Campus de Toledo.

E-mail: jhonathan.dias2019@outlook.com

${ }^{2}$ Graduado em Ciências Sociais (UNESP/Marília), Mestre e Doutor em Ciências Sociais (UNESP/Marília), professor no curso de Ciências Sociais na Unioeste, Campus de Toledo. E-mail: geraldomagellaneres@yahoo.com.br
} 


\section{Introdução}

Todo aquele que busca aprofundar-se nos caminhos da Ciência Política, em especial nas questões acerca da democracia, certamente em algum momento irá se deparar com a obra de Robert Michels, especialmente com a Sociologia dos Partidos Políticos, publicada originalmente em 1911. Não por acaso, mesmo após mais de 100 anos de sua publicação, a obra continua a representar uma contribuição fundamental nos estudos sobre a democracia e a representação política.

Robert Michels foi um sociólogo nascido em 9 de janeiro de 1876, na cidade de Colônia, Alemanha. Em virtude de sua origem de família burguesa, teve acesso a uma excelente formação acadêmica, tendo realizado seus estudos primários em Berlim e posteriormente seus estudos superiores em Paris, ingressando também nas universidades de Munique e Leipzig na Alemanha (JUSTO apud MICHELS, 2001).

Em sua juventude, Michels foi filiado ao Partido Socialdemocrata da Alemanha (SPD), partido que serviu como base para a investigação empírica e formulação de sua tese da "Lei de Bronze" da oligarquização das organizações complexas humanas. Como militante, a postura de Michels era a de um marxista ortodoxo, crítico radical ao revisionismo e a atuação excessivamente institucional e parlamentarista do partido, que almejava seu fortalecimento enquanto organização partidária e a conquista de cadeiras no Reichstag. Em contraposição, Michels defendia o uso de táticas mais próximas à ação revolucionária direta, bem como a criação de uma corrente do sindicalismo radical do partido (RIBEIRO, 2012).

Em decorrência de sua militância ao SPD, Michels encontrou dificuldade em estabelecer-se na Alemanha, tendo encontrado na Itália uma possibilidade para sua atuação, vindo a lecionar as disciplinas de Economia, Ciência Política e Sociologia, na universidade de Turim. Posteriormente, mudou-se para a Suíça, onde lecionou na área de Economia pela Universidade de Basel até 1926. Os últimos anos de vida de Michels se passaram na Itália, onde se formou Doutor e lecionou Economia e História das Doutrinas na Universidade de Perugia (JUSTO apud MICHELS, 2001).

O que torna Robert Michels um autor singular na história da teoria política é a trajetória conturbada de evolução de seu pensamento. Ou seja, inicialmente o pensamento de Michels caracterizase pela defesa do marxismo ortodoxo e pelo flerte com as teses do "sindicalismo revolucionário" (RIBEIRO, 2012), mas, posteriormente, abandona o marxismo, adotando o projeto de constituição de uma "ciência histórica analítica dos partidos políticos" (MIGUEL, 2014). O arco se fecha em 1923, quando ele filia-se ao Partido Nacional Fascista em 1923: o seu desenvolvimento teórico-político vai do marxismo revolucionário ao ideário de extrema-direita do fascismo mussoliniano.

O principal legado teórico de Michels decorre de sua capacidade quase profética de prever o futuro desenvolvimento das organizações partidárias num momento inicial de conformação dos grandes partidos operários europeus da primeira década do século XX. A sua proposição da "Lei de Bronze" da oligarquização e burocratização das organizações complexas - evidentemente que passível de crítica, principalmente, a partir de seus pressupostos fundamentais (conceito abstrato de democracia direta e cisão inevitável entre líderes e liderados) - que, mesmo sendo formulada no contexto de consolidação do fenômeno partidário na Europa, ainda assombra as instituições partidárias no Século XXI (NERES, 2012). A sua reflexão sobre as tendências à oligarquização dos partidos políticos mostrou-se tão eficaz no desenrolar da história da representação política que entrou para o "senso comum cultivado" (MIGUEL, 2014), transformando o livro de Michels num clássico da sociologia dos partidos políticos.

Em decorrência de sua capacidade "profética" e do estabelecimento de um senso comum cultivado, a obra de Michels é comumente evocada para indicar os limites que a própria natureza humana impõe sobre as diversas tentativas de organização democrática. A Lei de Bronze, com o passar dos anos, contando cada vez mais com exemplos empíricos, parece prescrever um caminho inevitável para o qual toda organização complexa tende a caminhar: a oligarquização. Mesmo considerando toda a 
argumentação para a realização desse caminho pelas instituições complexas, o presente artigo propõe outra perspectiva sobre a teoria michelsiana, sugerindo que, por meio do uso do contextualismo social, seja possível identificar na obra de Michels uma perspectiva para além da justificativa de abandono do ideal democrático, mas que seja considerada sua capacidade em questionar os aspectos não problematizados da representação política, servindo assim como um importante mecanismo de reflexão, no espinhoso caminho em defesa do ideal democrático, de forma que possamos questionar a atuação de todas as instituições humanas, inclusive aquelas que se dizem democráticas, mas que, em virtude das limitações humanas, acabam por sucumbir ao processo de oligarquização.

\section{Como e porque ler "sociologia dos partidos políticos" no século XXI}

Como constatado por Ribeiro (2012), tanto Robert Michels quanto sua obra Sociologia dos Partidos Políticos são muito mais citados e evocados do que realmente lidos ou conhecidos. Com o objetivo de superar a "superficialidade e o anacronismo" constantes nas referências à obra e ao autor em questão, propõe-se, neste artigo, uma abordagem pautada na contextualização social de Robert Michels, a fim de possibilitar uma maior compreensão dos conceitos estruturantes de sua obra.

Por meio da contextualização social considera-se de suma importância os fatores determinantes na estruturação da sociedade na qual Michels não somente viveu e escreveu, mas foi atuante pelo seu engajamento político diante das lutas e conflitos reais de sua época. Com o uso do contextualismo social, entende-se que o desenvolvimento da obra do autor esteve diretamente relacionado a fatores como: sua biografia, suas ideias e percepções sobre a política, as circunstâncias sociais e os acontecimentos históricos precedentes e contemporâneos em que viveu (CARDOSO; SILVA; NERES, 2016).

Por meio do contextualismo social proposto por Neal e Ellen Wood (1978), a pesquisa desenvolveu-se sob os pressupostos de que, em primeiro lugar, a política consiste num empreendimento eminentemente prático, estando diretamente ligado à vida cotidiana, onde a arena pública torna-se palco para as relações de poder entre indivíduos e grupos sociais, cada qual tendo como objetivo sua própria sobrevivência, mesmo que tal atuação apresente-se sob a prerrogativa de "interesse público ou do bem comum". Em consonância, o segundo pressuposto é o de que a teoria política está diretamente relacionada ao contexto social e histórico em que foi concebida (WOOD, 1978 apud CARDOSO; SILVA; NERES, 2016). Dessa forma, ao analisar a teoria das oligarquias, deve-se considerar que essa está atrelada organicamente ao contexto no qual foi desenvolvida, de forma que o fenômeno da oligarquização, caminho pelo qual diferentes organizações humanas tendem a caminhar, não pode ser compreendido como uma ideia universal e nem mesmo ser aplicada de maneira atemporal.

O terceiro pressuposto a ser considerado está no fato de que um texto clássico de teoria política caracteriza-se como uma importante reflexão sobre o seu tempo e o contexto no qual foi concebida, de forma que, ao nos oferecer importantes contribuições sobre a natureza de uma sociedade específica, pode também servir como um importante mecanismo de reflexão para o nosso próprio tempo e contexto (WOOD, 1978 apud CARDOSO; SILVA; NERES, 2016). Neste caso, entende-se que a obra de Michels, mesmo sendo formulada e desenvolvida sob condições e contextos específicos, pode ter um papel importante para que possamos analisar o desenvolvimento das organizações humanas no século XXI, em especial os partidos políticos e o sistema de democracia representativa.

O quarto pressuposto norteador considera que "A gênese de uma obra clássica de teoria política pode ser explicada em termos sociais, representando fundamentalmente uma posição partidária no conflito do período" (WOOD, 1978, p. 345 apud CARDOSO; SILVA; NERES, 2016, p. 20). A questão a ser levantada aqui é a seguinte: seria a obra de Robert Michels um mero instrumento, cujo objetivo partidário no conflito é o de nos levar ao abandono dos ideais democráticos, sob a prerrogativa de que a oligarquia é "a forma preestabelecida da vida em comum dos grandes agregados sociais"? (MICHELS, 1982, p. 235). Ou seria possível, por meio da apreensão dos diferentes conceitos que compõe a "Lei de 
Bronze das Oligarquias", utilizar o potencial da obra como um instrumento de reflexão sobre a organização dos processos e instituições que se dizem, ou pelo menos almejam, serem democráticos?

Para auxiliar na reflexão da questão em debate, utiliza-se também um quinto pressuposto, em que entendemos que "toda obra clássica de teoria política é ideológica", pois essas se formulam por meio de recomendações sociais e políticas constituídas intelectualmente e justificadas por meio de diferentes matrizes argumentativas, sejam elas científicas, epistemológicas, psicológicas, históricas, entre outras, mas que, no entanto, partem de interesses específicos de determinados indivíduos ou grupos sociais, que muitas vezes podem não ser de interesse de outros (WOOD, 1978 apud CARDOSO; SILVA; NERES, 2016). Dessa maneira, cabe a essa pesquisa identificar a natureza dos argumentos utilizados por Robert Michels para fundamentar a sua teoria sobre a oligarquização, bem como propor uma discussão tanto sobre a aplicabilidade dessa teoria em nosso próprio contexto como sobre a finalidade do autor em seu desenvolvimento, seja essa somente uma teoria que prega o abandono do ideal democrático por meio da crítica, seja essa teoria um importante mecanismo que, a partir dassuas críticas, possa nos auxiliar a repensar as organizações humanas no século XXI.

\section{A construção da "Lei de Bronze" de Robert Michels - Conceitos Estruturantes}

Como destacado por Ribeiro (2012), o pensamento de Robert Michels vai além da "monocausalidade" com a qual é corriqueiramente reduzido, sendo que seu pensamento é "muito mais complexo do que a assertiva 'quem diz organização, diz oligarquia'." A compreensão abrangente do pensamento de Michels demanda a identificação de diferentes períodos que marcam sua vida pessoal e, consequentemente, o desenvolvimento de sua obra.

Inicialmente, é possível identificar a atuação de Michels como um militante socialista, membro do Partido Social-Democrata Alemão (SPD) e, sobretudo, um marxista ortodoxo, que almejara o desenvolvimento de uma corrente de pensamento com base no sindicalismo radical (RIBEIRO, 2012). Posteriormente, após contato com diferentes influências intelectuais, bem como de sua entrada para a carreira acadêmica na Itália, o pensamento de Michels se desenvolve não mais na tentativa de construção de uma corrente de pensamento pelo qual era militante, mas na tentativa de produção de uma "ciência histórica analítica dos partidos políticos" (MIGUEL, 2014), passando a desempenhar o papel de um "Michels analista", o qual, após experiências práticas, parte para um realismo exacerbado, apontando os limites dos próprios movimentos que outrora integrou, como o socialismo e o sindicalismo radical, além das limitações práticas do anarquismo e a democracia liberal (RIBEIRO, 2012).

Para a compreensão desse processo de transição intelectual que culminou na ligação de pontos distintos como o Socialismo Revolucionário, presente na raiz do pensamento de Michels, chegando à adesão da corrente de pensamento do Fascismo no final de sua vida, é necessário identificar o modo como Michels compreendia alguns conceitos que com o decorrer do tempo, foram ressignificados pelo próprio autor. Dentre os principais conceitos estruturantes de sua obra, o ideal democrático estabelecido por Michels merece destaque, pois esse o acompanha e pode até se dizer que o norteia na ligação entre as distintas pontas de sua transição intelectual. Michels (1982) compreende a democracia como o "autogoverno" (self-government) das massas, sendo a vontade popular soberana nas decisões que afetam a vida em comunidade. Por esse motivo, seu ideal democrático se estabelece como a Democracia Direta, onde as questões pertinentes à sociedade devem ser debatidas em assembleias populares.

No entanto, mesmo concebendo como ideal democrático o "autogoverno" das massas, Michels admite a inviabilidade de realização da democracia direta em grandes agrupamentos, sendo esse o principal argumento contra a soberania das massas, em virtude de limitações mecânicas e técnicas para sua realização.

[...] Basta querer reunir regularmente assembleias deliberantes de milhares de membros para nos vermos às voltas com maiores dificuldades de tempo e de espaço. Mesmo imaginando-se meios de 
comunicação mais perfeitos do que aqueles de que dispomos, como seria possível reunir tamanhas multidões em um determinado local, em horas fixas e com a frequência que impõe as exigências da vida partidária (MICHELS, 1982, p. 17-18).

Em decorrência dos fatores de ordem técnica e mecânica cria-se a necessidade da existência de delegados, os quais se tornam responsáveis por representar e garantir a realização de sua vontade (MICHELS, 1982). Nesse ponto, Michels, sob influência do pensamento rousseauniano (MICHELS, 2001), compreende que a vontade humana, senão de maneira específica, não é passível de ser transmitida ou representada por outrem, sendo esse o problema primordial de um sistema de representação. Dessa forma, a delegação nada mais é do que a "abdicação ao exercício direto do poder pelo povo" sendo que "o povo, ao votar, faz um ato soberano, ao mesmo tempo em que renuncia sua soberania" (MICHELS, 1982, p. 23).

Tratando-se de um sistema democrático, Michels é arbitrário ao afirmar que "não se concebe a democracia sem a organização". Sejam reivindicações de âmbito econômico ou político, a organização aparece como o único mecanismo capaz de criar uma vontade coletiva, independente da classe a qual almeja trazer à tona suas reivindicações. Diante do cenário em que o sistema democrático apresenta-se como um campo de luta entre diferentes classes, as quais buscam sobrepor seus interesses, Michels compreende que uma organização eficiente pode se tornar um mecanismo de luta de uma classe oprimida contra sua opressora (MICHELS, 1982).

Em decorrência de sua atuação enquanto membro do SPD até meados de 1907, Michels carrega nas raízes de sua teoria uma grande influência do marxismo. Essa influência é perceptível em diferentes graus durante todo o desenvolvimento de sua obra, em especial, em sua fase como militante socialista, em que o conceito de democracia correspondia, de forma genérica, a uma revolução social, sendo essa a única estratégia viável para se fazer prevalecer a vontade geral. Os escritos primordiais de Michels correspondem à sua atuação dentro do SPD, onde integrava, sob o ponto de vista marxista, as alas mais ortodoxas, fazendo oposição às ideias revisionistas que se desenvolviam dentro do partido (RIBEIRO, 2012).

Como estratégia de atuação, o "Michels militante socialista" era extremamente crítico à postura institucional e parlamentar voltada ao fortalecimento do SPD enquanto mera organização partidária. Como alternativa, propunha a realização de táticas de ações diretas, bem como a criação de uma corrente sindicalista radical no partido, tendo como influência Rosa Luxemburgo e sua obra Greve de Massas, Partidos e Sindicatos (RIBEIRO, 2012).

Essa postura de atuação adotada por Michels dentro do SPD pode ser compreendida como prognóstico para suas críticas posteriores à “organização pela organização em si mesma", sendo um dos pilares de sua obra Sociologia dos Partidos Politicos. Suas críticas à atuação do SPD eram fundamentadas por um conjunto de pensadores de sua época, como Rosa Luxemburgo, além de demais sindicalistas radicais franceses $^{3}$ e em especial Gerges Sorel, com o qual manteve intensas relações intelectuais ao longo de sua carreira. Como aponta Ribeiro (2012), o objetivo de Michels com o passar do desenvolvimento de sua crítica à forma de organização e atuação partidária, torna-se o de criar uma teoria de ação política da classe operária com base na articulação de diferentes autores e correntes teóricas como Marx, Sorel, Proudhon e Pareto.

A transformação do pensamento e da obra de Michels pode ser compreendida por meio da mudança de seus locais de atuação e produção, bem como as relações pessoais e intelectuais que estabeleceu ao longo de sua carreira. Em primeiro momento, Michels tem sua atuação concentrada na vida e na produção de escritos partidários, no entanto, com o passar do tempo e a partir de novas relações, passa a dedicar-se em escritos de caráter acadêmico (RIBEIRO, 2012).

\footnotetext{
${ }^{3}$ Como apontado por (RIBEIRO, 2012), além de Georges Sorel, os principais sindicalistas influenciadores de Michels foram
} Hubert Lagardelle, Edouard Berth e Émile Pouget. 
Dentre os influenciadores mais importantes, Max Weber pode ser citado como um dos principais interventores no desenvolvimento do pensamento michelsiano. Não somente por meio de sua teoria com a Sociologia da Burocracia, mas também pelas relações pessoais, Weber foi tomado como um mestre por Michels. Ainda em sua juventude, em 1906, Michels foi convidado para integrar as produções da renomeada revista Archivfür Sozialwissenschaftund Sozialpolitik, na qual Weber atuara como editor. No entanto, devido à sua militância no SPD, obteve constantes restrições para ingressar nas instituições de ensino na Alemanha, de forma que nem mesmo sua relação próxima com Weber foi capaz de lhe garantir espaço de atuação na Alemanha (RIBEIRO, 2012).

Como possibilidade de atuação, mudou-se para a Itália, onde passou a lecionar as disciplinas de Economia, Ciência Política e Sociologia na Universidade de Turim. Com o exercício de suas atividades voltadas à academia, Michels deixa o SPD em 1907, bem como transforma suas produções de caráter militante, para desenvolver publicações em periódicos científicos de destaque. A partir desse momento, Michels passa a condensar as suas críticas à atuação das organizações democráticas em sua famosa obra da Sociologia dos Partidos Políticos, originalmente publicada em 1911 (RIBEIRO, 2012).

\section{Causas determinantes na formação de tendências oligárquicas nas organizações representativas - Fatores de ordem técnica e administrativas}

Diante de um sistema pautado sob o princípio da delegação, Michels desenvolve a sua teoria justamente na tentativa de elucidar os problemas decorrentes da representação, de forma que esse sistema, mesmo que tenha como propósito a ideia de democracia, não oferece "qualquer garantia contra a formação de um estado-maior oligárquico" (MICHELS, 1982, p. 17).

Nesse ponto, cabe ressaltar que Michels estabelece como seus adversários os dirigentes encarregados de representar a vontade popular, pois, como apontado pelo autor, esses possuem uma inclinação para a formação de oligarquias no decorrer da complexificação das organizações as quais pertencem. O fato de Michels ter constituído boa parte de sua teoria por meio da observação empírica do movimento operário, como os sindicatos e em especial o SPD, não significa que o autor busca combater por meio de suas críticas as organizações pautadas sob a teoria marxista, mas os dirigentes que constituíam as aristocracias operárias, seja em nome do marxismo, do socialismo ou da democracia (RIBEIRO, 2012).

No decorrer de sua obra, Michels dedica seus esforços para traçar o caminho pelo qual os dirigentes chegam à constituição das camadas oligárquicas. Esse caminho, quase que singular para a oligarquização, tem início conforme a organização em questão passa a assumir certo grau de complexidade, em que suas atividades tornam-se cada vez mais complexas e numerosas, havendo a necessidade de uma divisão e especialização do trabalho. Conforme a organização cresce, suas atividades administrativas se complexificam, de forma que "as obrigações aumentam e se especializam a ponto de se tornar impossível percebê-las numa visão de conjunto” (MICHELS, 1982, p. 22).

A grande crítica apontada por Michels nesse processo de especialização dos dirigentes está no fato de que, na medida em que a organização ganha solidez, torna-se necessária uma organização cada vez mais forte, tanto de forma tática como administrativa. Nesse processo, os chefes tendem a deixar de ocupar cargos meramente ocasionais para se transformarem em chefes profissionais. Mesmo que na teoria os chefes sejam empregados ligados às instruções da massa, a complexidade das atividades organizacionais leva ao partido confiar determinadas tarefas a determinados indivíduos, assim, o controle que inicialmente é reconhecido a toda a massa passa a ser confiado a funcionários especializados, sendo a massa "reduzida a contentar-se com prestações de contas sumaríssimas" (MICHELS, 1982, p. 22-23).

Michels compreende que esse processo de "metamorfose" entre uma direção ocasional e uma direção profissionalizada ocorre por meio de uma tendência natural, "pela força das coisas", em que, a partir do momento em que um chefe é tomado como especialista, habitua-se a resolver por conta própria 
as questões relacionadas à vida do partido, deixando de lado a consulta de opinião das bases. Essa eclosão de uma direção profissional marca para a democracia "o começo do fim" (MICHELS, 1982, p. 23). Essa crítica do sistema representativo vale especialmente para a vida moderna que se reveste todos os dias de formas mais complexas, e à medida que essas formas se complicam, torna-se cada vez mais absurdo querer "representar" uma massa heterogênea em todos os problemas criados pela crescente desigualdade da nossa vida política e econômica (MICHELS, 1982, p. 25).

Ainda sobre as causas determinantes de ordem técnica e administrativa, Michels compreende uma especificidade nos partidos modernos, em especial nos movimentos de caráter operário. Para o autor, o partido moderno é "uma organização de combate", no sentido político da palavra, em que as leis da tática, bem como a facilidade de mobilização são fundamentais para sua atuação. A disciplina rigorosa representa para um partido operário o único meio para ganhar estima e consideração dos partidos burgueses. Dessa forma, o partido democrático moderno atua de forma militante e demanda da centralização de suas decisões para que haja rapidez na execução de suas ordens na luta do dia a dia. Michels evoca o socialista holandês Van Kon para apontar que "a instauração da verdadeira democracia só será possível quando a luta estiver terminada” (MICHELS, 1982, p.27).

Michels compreende que a própria democracia é incompatível com a prontidão estratégica e, por esse motivo, os partidos modernos carregam nas raízes de suas atuações a necessidade de hostilidade e prontidão. Nesse sentido, o autor ítalo-germânico compreende que "a própria liberdade deve ceder diante da necessidade de uma ação pronta ou imediata" sendo a submissão das massas uma das mais altas virtudes democráticas (MICHELS, 1982, p. 27).

\section{Fatores determinantes de ordem Psicológica e Intelectual}

Para além das causas determinantes de ordem técnica e administrativa, Michels apresenta também causas determinantes de ordem psicológica que contribuem para as tendências de oligarquização das organizações humanas. O primeiro fator psicológico apresentado por Michels é o nascimento do direito moral à delegação. Esse fenômeno ocorre por meio de uma prática muito comum na democracia, em que, mesmo que as eleições sejam realizadas para determinar a atuação de um representante por um determinado tempo, essa atuação, com o processo de especialização, torna-se um cargo que se prolonga para o resto da vida. Dessa forma, "da delegação de fato nasce o direito moral à delegação", sendo que psicologicamente o hábito da atuação como chefe ou representante torna-se um direito (MICHELS, 1982, p. 31).

Michels utiliza-se da premissa de que, dentre os cidadãos que usufruem de direitos políticos, poucos são os que concebem o significado entre o bem individual e o bem coletivo. Para o autor, há uma apatia perante a massa com relação às atividades políticas, bem como grande desconhecimento dos assuntos que envolvem o Estado. O que Michels aponta é que, mesmo na vida dos partidos democráticos, o fenômeno da "indiferença política" continua a ocorrer, em que apenas uma minoria participa das decisões do partido (MICHELS, 1982, p. 33).

Dentre os motivos apontados por Michels para explicar a falta de assiduidade da massa para com as questões políticas, encontram-se as razões já citadas aqui de causa técnica, como a dificuldade em comparecimento de forma regular nas reuniões ordinárias, bem como a questão do cansaço físico e psicológico dos trabalhadores, que, após suas jornadas de trabalho, almejam repouso, tornando a participação política uma prática mais facilitada para indivíduos de classe média e pequeno-burgueses. Dessa forma, a massa encontra em seus representantes o reconforto da existência de indivíduos dispostos a cuidarem dos assuntos de bem público: "[...] A necessidade de serem dirigidas e guiadas é muito forte entre as massas, mesmo entre as massas organizadas do partido operário. E essa necessidade vem acompanhada de um verdadeiro culto aos chefes que são considerados como heróis" (MICHELS, 1982, p. 35). 
Michels evoca Marx para alertar os perigos da predisposição psicológica das massas para a subordinação, refletindo, assim, no excesso de confiança nas autoridades, bem como a ausência de qualquer senso crítico sobre suas ações. Como apontado pelo teórico alemão, há a necessidade de empenho no desenvolvimento do sentimento de independência dos operários, de forma que esses possam questionar a burocracia e as autoridades. Essa relação de dependência desenvolvida pelas massas perante seus representantes, aponta Michels, acarreta a criação de um obstáculo para a ampliação do poder dos partidos, pois as atividades práticas são corriqueiramente atribuídas aos dirigentes, e quando surgem as ocasiões que demandam ações diretas, como manifestações de protesto, os chefes são abandonados pelas massas (MICHELS, 1982, p. 36).

Outro fator apontado por Michels que contribui para a manutenção e a estabilidade dos chefes é a necessidade de veneração entre as massas. O autor ítalo-germânico aponta que essa necessidade é um resquício de uma psicologia primitiva, em que as massas sentem uma profunda "necessidade de se curvar" tanto para os grandes ideais como para os indivíduos que os representam. Essa veneração das massas se dá por meio da identificação de determinadas características presentes nos chefes que são capazes de cativar o grande público (MICHELS, 1982, p. 46).

Para além das causas de ordem psicológica que levam as massas a venerarem os seus chefes, outro fator que contribui para o estabelecimento de uma diferença entre líderes e liderados está na profissionalização desses dirigentes que, como consequência, desenvolvem certa superioridade intelectual em relação ao restante da massa. Como apontado por Michels (1982), a instrução formal se encontra junto a fatores como a superioridade econômica e a superioridade histórica, ou a tradição, na justificativa de dominação de minorias sobre as maiorias. Mesmo que o indivíduo em questão seja originário do segmento operário, ao encontrar meios e condições para seu próprio desenvolvimento intelectual, bem como ter acesso à remuneração e à ascensão de status, esse passa a distanciar-se e a perder a empatia para com a classe de onde saíram.

A crítica de Michels à atuação de caráter parlamentar dos partidos revolucionários se dá ao passo em que essas instituições, ao tomarem como objetivo a conquista dos poderes públicos, delegam seus representantes para comporem o corpo legislativo do Estado, e que, em decorrência desta atuação parlamentar em caráter profissional, afastam-se cada vez mais os chefes de seus eleitores. Com o aprofundamento das questões técnicas, os chefes tornam-se cada vez mais indispensáveis para os partidos, pois esses se tornam especialistas nas questões burocráticas, passando a reproduzir essa mesma burocracia no cotidiano dos partidos. Essa centralização de autoridade concebida aos dirigentes, em longo prazo, "destrói o próprio princípio da democracia", sendo a "incompetência incontestável das massas” a justificativa teórica para a dominação efetiva dos chefes (MICHELS, 1982, p. 55-56).

Michels admite nesse ponto que, em certo grau, o despotismo e certo desvio dos princípios da democracia pura correspondem a "um mal necessário", pois por meio do princípio da divisão do trabalho cria-se a especialidade e a especialidade corresponde à autoridade. A democracia dessa forma acaba por se transformar em uma forma de "governo dos melhores" numa aristocracia. "[...] Os chefes seriam tanto do ponto de vista objetivo como do ponto de vista moral, os mais capazes e os mais maduros; por isso eles teriam não só o direito, mas o dever de colocarem-se à testa da massa, e isso não só como representantes de um partido, mas como indivíduos fielmente conscientes de seu próprio valor pessoal" (MICHELS, 1982, p. 57).

\section{O Processo de dominação dos dirigentes sobre as massas}

Como ideal de aplicação dos princípios democráticos, Michels compreende que os partidos e organizações deveriam produzir condições para que as renovações dos cargos ocorressem de forma constante, tendo os antigos dignitários do partido sempre que ceder seus lugares para as forças jovens, de forma a impedir que os titulares de funções desenvolvam o sentimento de apego por seus cargos. No entanto, Michels, por meio de suas observações tanto dos partidos socialistas da Alemanha como também 
de outros países da Europa, constata que a solidez das organizações acaba por produzir um fenômeno de estabilidade, em que a "necessidade instintiva de um estado de coisas estável" acarreta um processo que as direções superiores passem a representar mais o passado do que o próprio presente. Além do sentimento de gratidão das massas perante seus chefes, o processo de especialização e profissionalização das funções contribui para a estabilidade deles. Sendo que "todo organismo burocrático repousa, pela sua natureza, sobre a divisão do trabalho" desenvolve-se a necessidade de comandantes que possuam experiência empírica para o desempenho de suas tarefas, o que assegura o processo de continuidade, em que o partido se vê obrigado a manter os mesmos chefes para desempenhar as mesmas funções (MICHELS, 1982, p. 65).

Ainda sobre o processo originário do caráter dominador dos chefes nas organizações, Michels identifica um interessante paradoxo ao que compreende a remuneração (ou não remuneração) dos funcionários partidários. Em suas análises, identifica que, diferentemente da grande maioria dos países europeus, o Partido Socialista Alemão contava com a "sorte" de ter chefes constantes e fiéis, sendo as deserções e traições fatos muito raros. Como exemplo contrário a tal "fidelidade", em países como a França e Inglaterra, não raras às vezes foi possível observar a transição de representantes populares para uma atuação que não mais privilegiasse os interesses de sua classe originária, mas que representassem os interesses governamentais e até mesmo os "inimigos mais ferozes" do proletariado. (MICHELS, 1982, p. 70).

Como justificativa para essa especificidade do movimento operário alemão, Michels aponta como os principais fatores a "pobreza de intelectuais" e também a existência de "indivíduos possuidores de uma independência econômica". Tais características protegeriam os chefes do partido socialista alemão das influências desagregadoras de divergências táticas, produzindo um status de similaridade entre os chefes e a massa. Além disso, a configuração política alemã como um Estado onde altos cargos da administração pública não eram definidos por um "soberano", inibiam a possibilidade de uma corrupção intelectual, e, por conseguinte, a mudança repentina de opinião e atuação dos chefes socialistas. Outro fator determinante para a manutenção da lealdade dos chefes para com os ideais do partido explica-se, segundo Michels, por razões de ordem material, ou seja, pela forma como o movimento operário alemão compreendera a necessidade de remuneração aos serviços prestados por seus servidores. Tal remuneração “imuniza seus servidores contra tentações grosseiras" (MICHELS, 1982, p. 72).

O grande paradoxo apontado por Michels está no fato de que mesmo o sistema de remuneração inibindo a formação de sentimentos de heroísmo e a devoção aos chefes por suas prestações de serviços, esse sistema é um fator contribuinte para o centralismo dentro dos partidos. Os chefes tornam-se financeiramente dependentes do partido, produzindo, assim, um sentimento de conservadorismo em seu seio. A prosperidade econômica de um partido e a boa remuneração dos chefes contribuem para alimentar "aptidões ditatoriais" daqueles que foram colocados à frente da organização e que ficam encarregados da administração do patrimônio coletivo (MICHELS, 1982).

Em decorrência da centralização do poder nas mãos dos dirigentes, Michels identifica que as próprias massas socialistas alemãs se convenceram de que as grandes batalhas decisivas são travadas no âmbito parlamentar. Dessa forma, as decisões tomadas pela casta de parlamentares tornam-se "inquestionáveis", na medida em que qualquer crítica, mesmo sendo feita em nome dos princípios do socialismo, é repudiada pela massa caso coloque em risco a soberania do grupo parlamentar. Nesse aspecto, Michels aponta para o fato de que a burocracia centralizada é capaz de desviar dos valores democráticos, até mesmo de movimentos operários que tem em sua essência o ideal democrático.

Ao pretender que só eles têm a faculdade de se pronunciar sobre uma eventualidade tão importante, e com mais forte razão se eles já possuem em grande parte este privilégio, os chefes cometem um atentado dos mais graves contra o mais fundamental dos princípios democráticos. Eles se constituem abertamente numa oligarquia e só reconhecem às massas, que fornecem os fundos, o dever de curvarem-se diante de suas decisões (MICHELS, 1982, p. 90). 
Esse acúmulo de poder nas mãos de uma minoria dirigente é entendido por Michels como "a fonte de todos os males", pois conforme um representante torna-se indispensável, esse fica sujeito a fatores de ordem pessoal, propenso a transformar-se de um servidor para um patrão do povo. Mesmo os partidos políticos que surgem sobre o pretexto de insurgir contra as "usurpações da autoridade constituída do Estado" sucumbem a uma necessidade natural de usurpações cometidas pelas autoridades formadas dentro de sua organização (MICHELS, 1982, p. 94).

A crítica exposta por Michels sobre a organização dos Partidos Socialistas é justamente sobre como os seus chefes desviam-se dos ideais democráticos, sucumbindo a atuações que se reduzem à busca pelo reconhecimento por parte da burguesia e do próprio governo. Os partidos atuam assim como ferramentas de moderação das massas, impedindo, nas palavras de Michels, "a revolução social”, revolução esta que possivelmente ocorreria com antecedência se não fosse a atuação estabilizadora dos dirigentes socialistas. A submissão das massas perante os seus chefes é muito maior do que a submissão em relação a um governo de Estado maior (MICHELS, 1982).

Essa ideia de força ilimitada dos chefes, mesmo que muito contundente, possui restrições. Como aponta Miguel (2014), Michels possui uma grande sensibilidade que o diferencia dos demais teóricos elitistas contemporâneos. Esse diferencial está no fato de que o autor ítalo-germânico traz para seu raciocínio principal a questão da relação entre os dirigentes para com as massas, considerando o fato de que os chefes estão teoricamente subordinados à vontade das massas. Mesmo considerando os diversos fatores que contribuem para a independência e estabilidade dos chefes, é inegável que nos partidos democráticos esses representantes sejam, em qualquer momento, removíveis e passíveis de substituição (MICHELS, 1982).

Michels ressalta que a característica essencial da democracia está no fato de que "cada um traz consigo um bastão de Marechal", ou seja, cada um dos membros de uma organização democrática tem a possibilidade de conquista de um cargo representativo, bem como tornar-se parte da direção dela. Neste sentido, a possibilidade de ascensão de novos chefes acarreta um alerta para os que já estão encarregados de tal cargo de representação das massas. A constância desse sentimento de instabilidade serve como um mecanismo que garante o contato entre o velho chefe com as opiniões e os sentimentos da massa (MICHELS, 1982).

Há, então, uma frágil e aparente submissão dos chefes perante as massas, que é condicionada quase que sempre em momentos onde seu poder encontra-se ameaçado pela ascensão de novos chefes. No entanto, tal submissão não passa de mera ação com o intuito de neutralizar a influência destes novos postulantes a dirigentes. Michels identifica, nesse contínuo processo de disputa entre postulantes e velhos dirigentes, que mesmo que haja divergências de cunho intelectual, a grande parte das disputas são travadas por princípios de ordem pessoal. Essas disputas individuais acarretam a delimitação da liberdade de discurso, em um processo de tendências conservadoras no qual os velhos chefes buscam censurar aqueles que divergem de suas sólidas opiniões. Os detentores do poder tornam-se os mais apegados pela disciplina, pela burocracia e pela subordinação, pois essas são as condições essenciais para a manutenção do partido como o é, de forma que garanta sua estabilidade. "Os revolucionários de hoje são os reacionários de amanhã" (MICHELS, 1982, p. 98).

Em decorrência desse processo de especialização, desenvolve-se entre os chefes a convicção de superioridade perante as massas, pois somente eles são capazes de analisar as questões pertinentes por meio de uma perspectiva puramente técnica. Esse "socialismo especializado" tende cada vez mais censurar todos aqueles que não fazem parte do corpo técnico, pois seus dirigentes consideram esses outros como intrusos e incompetentes. Sob influência do pensamento de Alfred e Max Weber, Michels concebe que o burocratismo existente dentro das organizações é o inimigo declarado das liberdades individuais. A dependência às autoridades sufoca as personalidades, produzindo um efeito de indigência moral (MICHELS, 1982, p. 106). 


\section{As Reações Psicológicas Decorrentes da Dominação dos Chefes Sobre as Massas}

Michels aponta que, mesmo aqueles operários os quais não almejam se tornarem dirigentes do partido, ao assumirem tal condição, não parecem dispostos a retornarem para a posição de "não dirigente" ocupada anteriormente. A justificativa para tal fenômeno está no desenvolvimento do sentimento de vaidade, em que "o desejo de dominar, para o bem ou para o mal, repousa no fundo da alma humana". Tal vaidade, somada à propensão humana para o estabelecimento de guias e dirigentes, provoca na psicologia dos chefes o sentimento de superioridade e a convicção de serem indispensáveis (MICHELS, 1982, p. 118).

Dessa forma, todo aquele que conquista o poder procura consolidá-lo, e na situação dos chefes que emergem das classes operárias, essa manutenção de cargos passa a ser necessária como forma de conservar os privilégios obtidos e a sua estabilidade financeira. Esses antigos operários já não estão mais habituados ao trabalho manual e considerando o fato de não possuírem uma fortuna pessoal, nem mesmo se quer outras fontes de renda, defendem com tenacidade o seu emprego, o qual considera como sua posse e bem inalienável (MICHELS, 1982).

Sob influência da teoria sindicalista de Sorel, Michels aponta para o fenômeno do Bonapartismo presente na atuação dos líderes referendados pelas massas e os compara aos aristocratas e a monarquia, onde a figura de Deus era a fonte de legitimidade do exercício da dominação, sendo que qualquer afronta a tais governantes significava uma afronta ao próprio Deus. No caso da democracia moderna, Michels aponta que os dirigentes sindicais e partidários se apoiam na legitimidade conferida pelas urnas, sendo que qualquer desobediência às ordens dos oligarcas representa, consequentemente, uma afronta ao princípio democrático (MICHELS, 1982).

O efeito derradeiro na psicologia do dirigente está no fato de este compreender a si mesmo como a própria emanação da vontade coletiva. Portanto, os interesses individuais se confundem com os interesses coletivos, sendo que a partir do momento em que o chefe compreende que "o partido sou eu", toda e qualquer crítica de um adversário mesmo que serena e justa, passa a ser compreendida tanto como um ataque à pessoa do dirigente como ao partido como um todo (MICHELS, 1982, p. 130).

\section{Análise Social do Fenômeno da Liderança}

Michels (2001), sob uma ótica marxista, compreende a luta de classes como o motor da história, sendo a consciência de classe o seu combustível. No entanto, afirma o autor (MICHELS, 1982), a massa é em grande parte insensível aos acontecimentos corriqueiros e às revoluções que se realizam no âmbito econômico, sendo esses somente perceptíveis com o passar do tempo, na medida em que se depara com novas condições de vida consequentes desses fenômenos. Nesse ponto, no que tange à luta de classes, uma classe oprimida somente aceita a sua situação de submissão em relação a outra pelo fato de não ser consciente da injustiça social que a oprime. "Não é a simples existência de condições opressivas, é a percepção delas por parte dos oprimidos que constitui a causa íntima das lutas de classes ao longo da história. É por isso que só a existência do proletariado moderno não é ainda suficiente para fazer nascer uma "questão social". Para que a luta de classes não permaneça no estado de vaga nebulosidade, de eterna latência, é preciso o substrato, por assim dizer, a consciência. Esta é condição indispensável daquela" (MICHELS, 1982, p. 136).

Tendo a consciência de classe como o papel de combustível para o motor da luta entre classes, Michels aponta o papel da doutrina socialista para que a classe operária possa tomar consciência de sua situação. Tal doutrina tem como raiz as reflexões de filósofos, economistas, sociólogos e historiadores e, a partir do momento que foi incrementado o uso da ciência a serviço da classe operária, torna-se um movimento cujo objetivo é a própria revolução proletária, sendo essa a única alternativa possível para uma transformação social efetiva. No entanto, aponta Michels, ao longo da história do socialismo, que 
foram os intelectuais advindos da classe burguesa os principais oradores na construção e formulação de tal doutrina (MICHELS, 1982).

Um dos fatores que contribuem para a atuação dos intelectuais de origem burguesa nos partidos socialistas é o fato de esses indivíduos possuírem vantagens sobre os proletários, como o tempo e os meios necessários para o desenvolvimento de sua educação política, bem como as condições materiais para o desenvolvimento dessa atividade política sem a dependência de outra atividade remunerada (MICHELS, 1982).

Para além das raízes intelectuais de origem burguesa, bem como a adesão de desertores da burguesia no movimento operário, Michels identifica que, conforme uma organização ganha corpo, produz consequências advindas de sua complexidade, de forma que com o seu desenvolvimento, passa a desempenhar uma série de transformações em seu meio social. Michels identifica nos partidos operários o desenvolvimento de um processo de "aburguesamento", fruto de três fenômenos complementares diferentes. Em primeiro lugar, em virtude da necessidade de efetividade eleitoral, os partidos acabam por procurar apoio da pequena burguesia, não mais condensando apenas os "irmãos operários de uniforme", deixando de ser um partido exclusivo de operários para tornar-se um partido do povo, almejando alcançar todas as camadas da sociedade (MICHELS, 1982).

O segundo fenômeno observado por Michels está nas consequências da própria organização da classe operária que acaba por formar novas camadas pequeno-burguesas no seio do partido. A própria necessidade de um efetivo especializado para desempenhar as atividades partidárias acaba por produzir uma elite operária, que, em decorrência de sua importância qualitativa, produzem uma metamorfose nos dirigentes de origem operária, os quais desenvolvem sentimentos e vaidades de ordem burguesa (MICHELS, 1982).

Para além dos fatores decorrentes da organização e da burocratização do partido, Michels aponta o terceiro fenômeno relacionado à necessidade de defesa patronal dos indivíduos, que, ao dedicarem-se à vida partidária, distanciam-se das atividades de trabalho manual, veem o partido como sua única fonte de renda e muitas vezes passam a desempenhar outras atividades que os aproximam das classes médias da sociedade (MICHELS, 1982).

A formação de uma pequena-burguesia de origem proletária, aponta Michels, consiste em um grande obstáculo "à marcha das falanges operárias". É da necessidade de diferenciação entre os indivíduos pertencentes da mesma classe operária, da formação de pequenos grupos reservados no seio do partido, que encontramos as raízes de tendência à oligarquia, fazendo oposição aos princípios teóricos do socialismo (MICHELS, 1982).

Esse processo de diferenciação entre os indivíduos desenvolve-se a partir das aspirações de todo operário em elevar-se para uma classe superior a qual lhe garanta uma melhor existência. Como fatores de diferenciação, Michels cita os diferentes tipos de trabalho, os níveis de salário e até mesmo as questões ligadas à "raça" que são capazes de produzir uma infinidade de nuances, tanto na forma de viver como nas vontades individuais dos operários. As diferenças de instrução, ocupação e remuneração formam no seio do partido uma aristocracia operária, em que aqueles que ocupam posições mais bem elevadas tendem a distanciarem-se dos outros, aproximando-se da burguesia e operando para a realização de uma tática propícia a seus interesses particulares e à manutenção de seus privilégios (MICHELS, 1982).

$\mathrm{Na}$ condição de dirigente, tanto os chefes de origem proletária quanto os desertores da burguesia apresentam as mesmas tendências oligárquicas, sendo que, no caso dos primeiros, o fator da ascensão social em decorrência sua atuação no partido amplia suas tendências de ambição pelo poder. Ocorre que o ex-proletário enxerga no exercício de sua direção do partido uma forma de se libertar da condição de servo do capital e procura, a partir de então, gozar de sua "liberdade" e muitas vezes acaba por abusar dessa (MICHELS, 1982). 


\section{A Crítica à Tese Michelsiana das Tendências Oligárquicas Nos Partidos Políticos - As Especificidades do Contexto}

Como demonstrado por Marenco e Noll (2012), a análise de Michels sobre a formação de oligarquias no seio das organizações partidárias deu-se num contexto onde tanto fatores de base social como institucional tornaram-se propícios à formulação de um solo fértil para o estabelecimento dessas oligarquias, especialmente nos partidos socialistas.

Em primeiro lugar, os fatores de base social podem ser compreendidos por meio da análise feita por Max Weber (1984a; 1984b), o qual teve influência direta no desenvolvimento do pensamento michelsiano. Em sua descrição sobre o cenário da Inglaterra até meados de 1968 (WEBER, 1984a, p. 1085), traçou o perfil dos indivíduos que se predispunham a desempenhar atividades políticas. No determinado contexto, predominavam os honoratiores, pastores anglicanos, professores, proprietários e artesãos. Para esses, a atividade política representava um meio de confirmar seu prestígio social, sendo essa apenas uma ocupação paralela. Dessa forma, o cenário político do século XIX não possuía grandes assimetrias, pois os partidos eram formados por notáveis, sendo o eleitorado censitário também formado por indivíduos de grande reputação, vindos de famílias tradicionais, possuidores de diplomas e proprietários de terras. A configuração de um sistema eleitoral reduzido, sendo representantes e representados possuidores de grandes semelhanças sociais e ideológicas, não forneciam incentivos para a formação de máquinas eleitorais com o objetivo de geração de finanças ou conquistas de votos, sendo que os custos das eleições eram suprimidos em decorrência de heranças familiares e os votos obtidos com base nas reputações e vínculos pessoais (MARENCO; NOLL, 2012).

Como observado por Weber (1984b) com a expansão do sufrágio, o cenário político de poucas assimetrias se transformou, pois foram incorporados na disputa candidatos que não possuíam fortuna pessoal, recursos ou se quer reputação social. A ascensão de representantes desprovidos de recursos sociais e econômicos demandava uma dependência material da atividade política para sua sobrevivência, sendo necessária a formação de máquinas partidárias capazes de garantir tais recursos para a atuação no meio político e a sobrevivência dos indivíduos voltados à causa partidária. Como forma de competir com partidários notáveis, os representantes de origem social mais baixa compensavam a disparidade de recursos e prestígio social por meio da dedicação à militância voluntária, bem como a adesão de programas e correntes teóricas ligadas pela identificação partidária, acarretando, assim, a ascensão dos partidos socialistas (MARENCO; NOLL, 2012).

Para além dos marcos de base social, a expansão do sufrágio em conjunto com a ascensão dos partidos socialistas provocou alterações de base institucional nos processos eleitorais em todo o continente Europeu ${ }^{4}$. O cenário político que antes era marcado por poucas assimetrias sociais e pautado por meio de procedimentos de voto majoritário, sendo esses convertidos em cadeiras parlamentares, foi rapidamente alterado para a aplicação de sistemas de base proporcional, em sua maioria pautados em ordenamentos prévios de candidatos partidários, como forma de listas fechadas.

Em análise aos movimentos de alteração dos processos eleitorais da fórmula majoritária para a representação proporcional, Boix (1999) compreende tais modificações como parte da estratégia das elites políticas em contraposição à ascensão dos partidos socialistas. Ocorre que, nos sistemas majoritários, os partidos de notáveis seriam obrigados, em oposição aos partidos socialistas, a disputarem o mesmo eleitorado entre si, de forma que tal processo acarretaria a formação de governos com bases socialistas, pois esses contavam com sua ascendência e constituiriam a maioria parlamentar. Por esse motivo, a alteração dos sistemas eleitorais serviu como mecanismo de distribuição dos cargos legislativos de forma

\footnotetext{
${ }^{4}$ Como exemplo, a Bélgica, após a adoção do sufrágio universal masculino em 1885, levou somente quatro anos para aplicar a reforma de representação proporcional de listas fechadas (1889). Na Suécia foram necessários 20 anos entre um fenômeno e outro (1889 - 1909). Adiante, a adesão ao sistema proporcional de listas pré-ordenadas foram anotadas também na Áustria (1918), Alemanha (1919), França (1919), Holanda (1918) Itália (1919) e Irlanda (1922) (MARENCO; NOLL; 2012).
} 
proporcional, possibilitando aos partidos de notáveis manterem-se solidificados nas casas parlamentares podendo coordenar suas ações posteriormente ao período eleitoral. (MARENCO; NOLL, 2012).

A especificidade do contexto em que a obra de Robert Michels foi desenvolvida está no fato de que, como apontam os registros de reformas eleitorais entre os séculos XIX e XXI (COLOMER, 2003; MARENCO, 2006), 50\% dos processos de adoção ao voto proporcional combinado com listas fechadas ocorreram justamente nesse período, caracterizando esse como um fenômeno muito específico da época. Os fatores relacionados ao alargamento do sufrágio e a introdução no cenário político de um novo perfil de eleitores e candidatos deram espaço para a criação de organizações que demandavam suprir as necessidades de captação de recursos de forma a tornar competitiva a disputa com os tradicionais partidos de notáveis. Considerando que as instituições partidárias, em especial os partidos socialistas, encontravam-se em seu estado mais avançado do processo de consolidação justamente nas décadas em que Michels desenvolveu as suas análises, podemos considerar que esse fenômeno possui grande influência na perspectiva do autor, que, em sua obra, dedica-se justamente a apontar os riscos decorrentes da complexificação das instituições partidárias.

\section{As Limitações da Teoria Elitista - A Especificidade de Robert Michels}

A obra de Robert Michels é comumente evocada como um instrumento para indicar os limites da própria natureza humana nas diversas tentativas de constituição de organizações democráticas. A forma corriqueira como a obra é utilizada a coloca como integrante da galeria de teóricos elitistas, ao lado de Vilfredo Pareto e Gaetano Mosca. No entanto, ao analisar a metodologia de trabalho e o desenvolvimento da Lei de Bronze, são perceptíveis alguns fatores que diferem Michels dos demais elitistas, aproximando-o mais da corrente teórica do conservadorismo.

Como apontado por MIGUEL (2014, p), o elitismo pode ser compreendido por meio da afirmativa de que a realização de uma sociedade mais igualitária é um fenômeno impossível de ser realizado. Tal corrente teórica parte do pressuposto de que a estruturação da sociedade entre uma minoria governante e uma maioria a ser governada é uma constante universal, presente em toda sociedade humana, seja no passado, no presente e até mesmo no futuro. Entende-se que toda tentativa de alterar essa estrutura está fadada ao fracasso e mesmo aqueles que proclamam a realização de movimentos políticos com finalidades igualitárias estão presos a uma constante em que somente renovarão as formas de dominação, mas a dominação de uma minoria permanecerá intacta.

No entanto, a concepção elitista de impossibilidade de uma ordem social igualitária não pode ser confundida com as afirmativas de existência de uma desigualdade natural entre os seres humanos ou a necessidade de lideranças pautadas por características individuais. Tais afirmações se encaixam na corrente teórica do conservadorismo, a qual compreende as desigualdades como fruto da própria natureza humana, sendo a governança uma atividade que deve ser destinada a uma minoria capacitada. A diferença fundamental entre ambas as correntes teóricas está no fato de que, como exposto por Edmund Burke (1982), o conservadorismo não trata sobre a imutabilidade da ordem social, mas adverte para os riscos de subvertê-la (MIGUEL, 2014).

Mesmo estando presente em ambas as correntes de pensamento, a ideia de uma minoria que exerce poder sobre a massa possui diferentes formas de aplicação. Ao analisar a história, pode ser destacada a existência de uma minoria governante na Democracia Ateniense do século IV a.C., nas monarquias absolutistas na Europa do século XVII, na Alemanha Hitlerista entre 1933 e 1945, e até mesmo no Brasil do século XXI. No entanto, mesmo compartilhando do fenômeno de uma minoria governante, cada um desses períodos históricos possui características próprias, de forma que não seria correto reduzi-los a meras manifestações decorrentes de uma mesma característica que atravessa a história ao longo do tempo (MIGUEL, 2014). 
A corrente de pensamento elitista pautada sob um pressuposto de uma constante universal que define a impossibilidade de realização de uma ordem social igualitária ignora uma infinidade de fatores determinantes na estruturação da sociedade ao longo da história. São deixados de lado questionamentos fundamentais sobre a origem e os meios como são estabelecidos os governantes, além de toda a complexidade existente na relação entre esses e os governados, como os diferentes interesses e mecanismos de controle e supervisão. Ao analisar o contexto, nota-se que a teoria das elites ganha destaque justamente no período marcado pela ascensão de movimentos democráticos e dos partidos socialistas que reivindicavam a superação das desigualdades sociais, sendo possível apontar que essa corrente teórica adotou um papel de contraposição às propostas de superação da desigualdade, servindo como mecanismo para amenizar os diversos movimentos que surgiram por toda a Europa. Analisada de forma mais contundente, a teoria das elites mostra-se "circunscrita historicamente", "simplista teoricamente" e "equivocada empiricamente" (MIGUEL, 2014, p. 143).

Diante das limitações da teoria das elites, a contribuição de Robert Michels apresenta especificidades que o difere dos demais teóricos elitistas. A primeira dessas especificidades está na metodologia de trabalho adotada por Michels, que, ao contrário de Pareto e Mosca, não desenvolveu a sua obra por meio de uma teorização geral, selecionando exemplos na história da humanidade para moldar à sua teoria. A Lei de Bronze das oligarquias de Michels é constituída por meio de uma generalização a partir de um estudo minucioso de um contexto específico, no caso a análise das organizações partidárias e a social-democracia alemã. Em virtude de sua imersão em um contexto específico, Michels foi capaz de captar de forma mais sensível a importância da relação entre dirigentes e as massas. Em sua análise sobre as questões decorrentes da representação, Michels compreende a formação das oligarquias não por meio da autoinstituição, mas sim, por meio de um processo em que há a importância da base social, que, em virtude de fatores técnicos, administrativos e psicológicos, transfere o poder para representantes. A questão diferencial apresentada por Michels não parte da impossibilidade de realização de uma sociedade mais igualitária, mas sim dos problemas decorrentes das organizações de massa, que, em virtude de um contexto exigente de uma eficácia e prontidão das ações políticas, demanda a profissionalização das atividades políticas, comprometendo a relação entre dirigentes e a base (MIGUEL, 2014).

Mesmo com sua sensibilidade específica, podemos dizer que Michels peca por certo simplismo em sua análise da relação entre dirigentes e as massas. A especialização dos funcionários na tese michelsiana leva a um caminho singular de perda de solidariedade para com os membros da base do partido, acarretando um processo de mudanças de posição nas relações sociais de produção. A afirmação de que "é uma lei social inelutável que qualquer órgão da coletividade, nascido da divisão do trabalho, cria para si, logo que estiver consolidado, um interesse especial" (MICHELS, 1982 p. 234) ignora fatores determinantes nas motivações dos dirigentes, reduzindo-as como consequentes de questões individuais, não levando em conta a interferência de projetos ou valores políticos que transcendem a essa individualidade. 


\section{Considerações Finais}

Em uma análise mais prudente sobre a trajetória de Robert Michels, evidencia-se o desdobramento de um processo de transição intelectual, refletindo, assim, no desenvolvimento de sua obra, em especial, na sua Sociologia dos Partidos Políticos. Em um primeiro momento, a militância pelo SPD e, sobretudo, a fidelidade a um marxismo ortodoxo, encaminharam Michels para uma tentativa de construção de uma corrente de pensamento com base no sindicalismo radical (RIBEIRO, 2012). Neste ponto, o ideal democrático estabelecido por Michels está no "autogoverno" das massas, sendo a vontade popular soberana nas decisões da vida em comunidade. Para este Michels militante, a revolução social seria a única estratégia viável para se fazer prevalecer o conceito de democracia (MICHELS, 1982).

No decorrer de sua militância, Michels volta-se para a crítica à postura institucional parlamentar do SPD, onde, a partir de então, passa a desenvolver seus apontamentos sobre "a organização pela organização em si mesma". O objetivo passa a ser o desenvolvimento de uma teoria de ação política da classe operária com base na articulação de diferentes autores e correntes teóricas como Marx, Sorel, Proudhon e Pareto (RIBEIRO, 2012).

O que pode ser compreendido como um dos fatores primordiais na transição intelectual de Michels é a sua mudança para a Itália e o ingresso na Universidade de Turim. Com o exercício das atividades acadêmicas, os panfletos de caráter militante ficaram de lado, dando lugar para $\mathrm{O}$ desenvolvimento de publicações com caráter científico, onde Michels passa a concentrar seus esforços no desenvolvimento de uma ciência histórica analítica dos partidos políticos (MIGUEL, 2014).

Por meio da metodologia do contextualismo social proposta por (WOOD, 1978), partimos da compreensão de que a teoria política está diretamente relacionada ao contexto no qual foi concebida. No caso da teoria michelsiana, é possível evidenciar a existência de fatores tanto de bases sociais quanto institucionais muito específicos de sua época (MARENCO; NOLL, 2012). A expansão do sufrágio ocasionou uma completa transformação no cenário político (WEBER, 1984b), promovendo a ascensão de representantes desprovidos de recursos sociais e econômicos, o que demandava a formação de grandes máquinas partidárias capazes de garantir o financiamento de recursos para a atuação no meio político.

Em contraposição à ascensão dos partidos socialistas, as elites políticas por toda a Europa promoveram movimentos para alteração nos processos eleitorais, onde a fórmula majoritária foi substituída pela representação proporcional (BOIX, 1999). A combinação de tais fatores, específicos ao contexto de Michels, produziram um cenário em que as instituições partidárias, em especial os partidos socialistas, encontravam-se em seu estado mais avançado no processo de consolidação, o que certamente teve influência na perspectiva de Michels no desenvolvimento de sua obra, que trata justamente sobre os riscos da complexificação das instituições partidárias. Para Michels, em decorrência do desenvolvimento da organização, conforme ela ganha complexidade, há a necessidade de divisão e especialização do trabalho, havendo consequentemente o acúmulo de poder nas mãos de uma minoria dirigente. Esse processo, com o passar do tempo, é compreendido como "a fonte de todos os males" rumo a um processo de oligarquização (MICHELS, 1982, p. 94).

Mesmo diante das especificidades de período histórico em que Michels esteve inserido, o contextualismo social compreende um texto clássico de teoria política, por meio de sua reflexão sobre o seu próprio tempo, oferece-nos importantes contribuições sobre a própria natureza humana, de forma que pode nos servir como um importante mecanismo de reflexão para o nosso próprio contexto. Neste sentido, mesmo diante das tendências de simplificação de Michels em sua tentativa de construção de uma "lei de bronze das oligarquias", não podemos negar o valor de sua obra como um importante mecanismo de reflexão sobre os dilemas de um sistema representativo diante da configuração da vida moderna, que a cada dia se reveste de formas mais complexas, e que, em decorrência das desigualdades da vida política e econômica, produz uma massa cada vez mais heterogênea, sendo a prática da representação cada vez mais difícil de ser desempenhada. 
Diante dessas complicações, uma das grandes contribuições de Michels para reflexão do sistema representativo está em seus apontamentos sobre a necessidade de eficiência no jogo político. Ao analisarmos a dinâmica dos processos eleitorais contemporâneos, é possível identificar uma série de fatores que contribuem tanto para uma centralização excessiva de poder nas mãos de dirigentes como para o afastamento das bases dos programas partidários e que, mesmo havendo tentativas das organizações políticas em combater as tendências centralizadoras, essas se defrontam com a necessidade de eficácia e prontidão de suas ações.

Um grande mérito na teoria de Michels está na sua capacidade de questionar aqueles que se dizem em prol da construção de uma democracia a nível de Estado, mas que, ao mesmo tempo, conduzem seus partidos para a formação de oligarquias (RIBEIRO, 2012). Michels não descarta a necessidade da centralização dentro dos partidos políticos, pois compreende a organização como mecanismo capaz um direcionamento coletivo, sendo primordial para as reivindicações de âmbito econômico e político. O que Michels atenta é para os perigos decorrentes desta centralização e levanta a reflexão justamente sobre as soluções ilusórias que nos são apresentadas, de forma que não é suficiente a idealização de um modelo livre da centralização do poder, como também é preciso questionar os meios pelos quais tal idealização será colocada em prática.

Como apontado por (MIGUEL, 2014, p.150), "Há autores que contribuem para vislumbrar alternativas, que ajudem a indicar a potencialidade de mudança no mundo real. [...], mas há autores que são como âncoras que nos impedem de nos perder no sonho de 'outro mundo possível". Desta forma, a contribuição realista de Michels não deve ser compreendida como mera visão fatalista de impossibilidade de efetivação da democracia, muito menos como uma lei social imutável. A teoria das oligarquias pode ser compreendida como um importante mecanismo para a reflexão da relação entre representantes e representados, bem como para a compreensão da complexidade que envolve um sistema democrático representativo, ajudando-nos a questionar soluções simplistas que possam acabar perpetuando as relações assimétricas entre representantes e as massas. 


\section{Referências}

BOIX, Carles. Setting therules of the game: thechoice of electoral systems in advanceddemocracies. American Political Science Review, v. 93, n. 3, p. 609-624, set. 1999.

COLOMER, J. Handbook of electoral system choice. Nova Iorque, Palgrave-Macmillan, 2003.

CARDOSO, Juliane Cristina Helanski; SILVA, Vania Sandeleia Vaz da; NERES, Geraldo Magella. Como estudar teoria política: textualismo, contextualismo linguístico e contextualismo social. V Simpósio Paranaense de Ciências Sociais, 5., 2016. Anais... Toledo: Universidade Estadual do Oeste do Paraná, 2016, pp. 63-85.

LUXEMBURGO, Rosa. Greve de massas, partido e sindicatos. Coimbra: Centelha, 1974.

MARENCO, André. Regras eleitorais importam? Modelos de listas eleitorais e seus efeitos sobre a competição partidária e o desempenho institucional. Dados - Revista de Ciências Sociais, v.49, n.4, p. 721-749, 2006.

MARENCO, André; NOLL, Maria Izabel. Décadas de Michels: marcos contextuais e prazo de validade para a "lei de ferro". Rev. Sociol. Polit., v. 20, n. 44, p. 63-72, nov. 2012.

MICHELS, Robert. Sociologia dos partidos políticos. Brasília: Universidade de Brasília, 1982.

2001.

Para uma sociologia dos partidos políticos na democracia moderna. Lisboa: Antígona,

MIGUEL, Luis Felipe. Oligarquia, democracia e representação no pensamento de Michels. Rev. Bras.

Ciênc. Polít., n. 13, p. 137-154, abr. 2014.

NERES, Geraldo Magella. Gramsci e o “moderno Príncipe”: a teoria do partido nos Cadernos do cárcere. São Paulo: Cultura Acadêmica, 2012.

RIBEIRO, Pedro Floriano. Realismo e utopia em Robert Michels. Rev. Sociol. Polit., v. 20, n. 44, p. 31 46, nov. 2012.

WOOD, Neal. The social history of political theory. Political Theory, v. 6, n. 3, ago. 1978.

WEBER, Max. Economia y sociedade. Cidade do México: Fondo de Cultura Económica, 1984a.

Ciência e política: duas vocações. São Paulo: Cultrix. 1984b. 